\title{
Does the light source affect the repairability of composite resins?
}

Emel KARAMAN Nihan GÖNÜLOL

Department of Restorative Dentistry, Faculty of Dentistry, Ondokuz Mayıs University, Samsun, Turkey.
Declaration of Interests: The authors certify that they have no commercial or associative interest that represents a conflict of interest in connection with the manuscript.

Corresponding Author:

Emel Karaman

E-mail:dtemelc@yahoo.com

DOI: 10.1590/1807-3107BOR-2014.vol28.0027 Epub XxX XX, 2014

Submitted: Sep 04, 2013

Accepted for publication: Mar 13, 2014

Last revision: Jun 30, 2014
Abstract: The aim of this study was to examine the effect of the light source on the microshear bond strength of different composite resins repaired with the same substrate. Thirty cylindrical specimens of each composite resin-Filtek Silorane, Filtek Z550 (3M ESPE), Gradia Direct Anterior (GC), and Aelite Posterior (BISCO)-were prepared and lightcured with a QTH light curing unit (LCU). The specimens were aged by thermal cycling and divided into three subgroups according to the light source used-QTH, LED, or PAC $(\mathrm{n}=10)$. They were repaired with the same substrate and a Clearfil Repair Kit (Kuraray). The specimens were light-cured and aged for 1 week in distilled water at $37^{\circ} \mathrm{C}$. The microshear bond strength and failure modes were assessed. There was no significant difference in the microshear bond strength values among the composite resins, except for the Filtek Silorane group that showed significantly lower bond strength values when polymerized with the PAC unit compared to the QTH or LED unit. In conclusion, previously placed dimethacrylate-based composites can be repaired with different light sources; however, if the composite to be repaired is silorane-based, then using a QTH or LED device may be the best option.

Keywords: Composite Resins; Dental Debonding; Dental Restoration Failure.

\section{Introduction}

Despite their continued development, composite resins can demonstrate degradation in the oral environment over time. Marginal deficiencies, fracture, and wear are the main reasons for deterioration, which can lead to secondary caries or tooth sensitivity. ${ }^{1,2}$ The traditional treatment of defective composite restorations, including removing and replacing complete restorations, is not desirable because this approach widens the prepared cavity, results in greater loss of sound tooth structure, and may lead to pulpal symptoms. ${ }^{3}$ As a conservative alternative to complete replacement, the repair of preexisting restorations has become an important treatment option in modern dentistry. This technique can increase the longevity of the restoration, avoid unnecessary removal of sound tooth tissues, and reduce repeated irritations or injuries to the pulp. ${ }^{4}$

In response to the dramatic rise in the use of composite resins, there has been substantial scientific interest in polymerization. Many light-curing units (LCUs) have been developed. ${ }^{5,6}$ Until recently, quartz-tungstenhalogen $(\mathrm{QTH})$ LCUs were primarily used to polymerize composite res- 
ins. However, despite their common use, QTH units have some shortcomings, such as the limited lifespan of halogen bulbs (40-100 h) and degradation of the components (bulb, reflector, and filter) over time due to the high operating temperature.?

To overcome some of these shortcomings, the use of light-emitting solid-state diode (LED) technology was proposed in the mid-1990s. ${ }^{8}$ Instead of the hot filaments used in halogen bulbs, LEDs use junctions of doped semiconductors to generate light. LEDs do not require filters as the spectral output because the blue LED falls within the absorption spectrum of the camphorquinone photoinitiator $(400-500 \mathrm{~nm})$. LEDs have an expected lifetime of more than $10,000 \mathrm{~h}$, during which the light flux undergoes little degradation. ${ }^{9}$ The degree of monomer conversion produced by a blue LED source was reported to be significantly higher than that produced by a QTH source, even when all sources were adjusted to produce the same irradiance $\left(100 \mathrm{~mW} / \mathrm{cm}^{2}\right) .^{10}$ Plasma arc light-curing units (PAC units) are another choice. PAC light is emitted from glowing plasma, which is composed of a gaseous mixture of ionized molecules (e.g., xenon) and electrons. ${ }^{11}$ Due to their higher light intensity, PAC lights cure composite resins at a much faster rate than conventional QTH LCUs and may be a time-saving alternative. ${ }^{12}$

Several recent in vitro studies have analyzed the effects of different adhesive intermediates, surface preparation methods, and combinations of composite resins on the reparability of composite restorations. ${ }^{13,14,15}$ However, to the best of the authors' knowledge, no study has evaluated the effect of the light source used on composite repair. Thus, the aim of this in vitro study was to evaluate the effect of different light sources on the microshear bond strength of aged composite repairs when the same substrate was used. The null hypothesis tested was that the type of light source does not affect the microshear bond strength.

\section{Methodology}

\section{Preparation of Aged Composite Specimens}

The composite resins used in the current study are shown in Table 1 . For each composite material, 30 cylindrical specimens ( $10 \mathrm{~mm}$ diameter $\times 2 \mathrm{~mm}$ thickness) were prepared in Teflon ring molds. Each mold was positioned on a glass microscope slide before being filled with composite resin and covered with a Mylar strip. A second microscope slide was pressed firmly onto the composite to remove excess material. All of the composite specimens were bulk-cured without layering by a QTH LCU (intensity $=650 \mathrm{~mW} / \mathrm{cm}^{2}$ ), according to the manufacturers' instructions. Polymerized specimens were stored in distilled water at $37^{\circ} \mathrm{C}$, to replicate the oral condition, for $24 \mathrm{~h}$. Thereafter, they were polished with a series of aluminum oxide polishing discs (Sof-Lex, 3M ESPE, Dental Products) under constant water cooling.

Specimens were aged by thermal cycling for 5,000 cycles between two water baths maintained at $55 \pm 1$ and $5 \pm 1{ }^{\circ} \mathrm{C} .{ }^{16}$ All specimens were embedded in autopolymerizing acrylic resin. Before the repair procedure, they were roughened with 320-grit silicon carbide paper, to obtain a similar roughness as that obtained by diamond bur grinding.

\section{Repair Procedure}

Specimens were randomly divided into three subgroups $(\mathrm{n}=10)$, according to the LCU used: QTH, LED, or PAC (Table 2). In all cases, the LCUs were used in the standard mode and positioned $1 \mathrm{~mm}$ above the composite resin surface with a metal ring. A Clearfil Repair Kit (Kuraray Medical, Inc., Okayama, Japan) was used as an intermediate agent in all study groups. Before bonding, Ketchant gel (40\% phosphoric acid gel) was applied for $10 \mathrm{~s}$, followed by rinsing with water and airdrying for $20 \mathrm{~s}$. A 1:1 mix of porcelain bond activator and Clearfil SE Bond primer was applied, followed by

Table 1. Composite Resins Used in the Current Study.

\begin{tabular}{|c|c|c|c|c|}
\hline Product & Type & Batch \# & Shade & Manufacturer \\
\hline Aelite LS Posterior & Low-shrink hybrid & 1200002086 & A2 & Bisco, Inc., Schaumburg, IL, USA \\
\hline Gradia Direct Anterior & Micro hybrid & 1107232 & $\mathrm{~A} 2$ & GC Corp., Tokyo, Japan \\
\hline Filtek Z550 & Nano hybrid & N311490 & $\mathrm{A} 2$ & 3M ESPE, St Paul, MN, USA \\
\hline Filtek Silorane & Low-shrink & N361058 & $\mathrm{A} 2$ & 3M ESPE, St Paul, MN, USA \\
\hline
\end{tabular}


Table 2. Light-Curing Units and Curing Times Used in the Current Study.

\begin{tabular}{|c|c|c|c|c|c|c|c|}
\hline \multirow{2}{*}{ Curing unit (Manufacturer) } & \multirow{2}{*}{ Light source } & \multirow{2}{*}{$\begin{array}{l}\text { Irradiance } \\
\left(\mathrm{mW} / \mathrm{cm}^{2}\right)\end{array}$} & \multicolumn{5}{|c|}{ Curing time (s) } \\
\hline & & & Intermediate & Aelite & Gradia & Z550 & Silorane \\
\hline $\begin{array}{l}\text { Smart Lite (Benlioglu Dental, } \\
\text { Ankara, Turkey) }\end{array}$ & QTH & 650 & 20 & 40 & 40 & 40 & 40 \\
\hline $\begin{array}{l}\text { Elipar FreeLight } 2 \text { ( } 3 M \text { ESPE, St. } \\
\text { Paul, MN, USA) }\end{array}$ & LED & 1000 & 10 & 20 & 20 & 20 & 20 \\
\hline $\begin{array}{l}\text { Monitex Plasma Star SP-2000 } \\
\text { (Monitex Industrial Co., Ltd, San- } \\
\text { Chung City, Taipei, Taiwan) }\end{array}$ & PAC & 1800 & 3 & 6 & 6 & 6 & 6 \\
\hline
\end{tabular}

a thin layer of Clearfil SE Bond. A silicone tube $(0.8 \mathrm{~mm}$ internal diameter $\times 0.5 \mathrm{~mm}$ height) was placed on the bonded area and light-cured. The adhesive resin was light-cured, and then the tubes were filled with composite resin and polymerized as described in Table 2. Specimens were stored in distilled water at $37^{\circ} \mathrm{C}$ for 1 week before the microshear bond test was performed.

\section{Microshear Bond Strengths and Failure Analysis}

The bond strength was tested with a universal testing machine (LRX, Lloyd Instruments, Ametek Inc., Leicester, UK) at a crosshead speed of $1.0 \mathrm{~mm} / \mathrm{min}$. Load at debonding was recorded in Newtons (N). The microshear bond strength was calculated by dividing the load at debonding by the bonded area $\left(\mathrm{mm}^{2}\right)$. For failure mode analysis, the debonded area was examined by stereomicroscopy at $40 \times$ magnification. The failure mode was classified as adhesive (if failure occurred at the interface), cohesive (if failure affected at least parts of the substrate or the repair composite), or mixed..$^{17}$

\section{Statistical Analysis}

TheShapiro-Wilk test was used to verify the normal distribution of the data. Then, one-way analysis of variance (ANOVA) was performed in a completely randomized design, $\hat{Y}_{i j}=\mu+a_{i}+e_{i j}$ where $\hat{Y}_{i j}$ is the observation value (MPa), $\mu$ is the overall mean, $a_{i}$ is the effect of the treatment (composite or light source), and $e_{i j}$ is the residual error. The Tukey multiple range test was utilized to separate these differences. All computational work was performed in MINITAB (Minitab V. 13.20, 2000).

Chi-squared $\left(\chi^{2}\right)$ analysis was applied to analyze whether the failure mode statistically depended on the composite resin or light source. If a relationship was identified, then contingency coefficients (\%) for each contingency table were calculated to determine the degree of association between the failure mode and the composite resin or light source. The Z-test was utilized to determine any further association.

\section{Results}

Results of the microshear bond strength tests are summarized in Table 3. The Filtek Z550 group showed the highest bond strength values when the QTH source was used for polymerization, followed by the PAC and LED sources, albeit without statistical significance among the subgroups. Similarly, in the Gradia Direct Anterior group, the QTH and LED sources produced the highest and lowest bond strength values, respectively, but the difference between them was not significant. All three light sources produced similar bond strength values for the Aelite group. PAC resulted in the lowest bond strength values in the Filtek Silorane group among the light sources used $(p<0.001)$.

Table 3. Mean and Standard Deviation Values of Microshear Bond Strength(MPa)for Each Group.

\begin{tabular}{lcccc}
\hline Group & QTH & LED & PAC & $p$-value \\
\hline Z550 & $23.51^{\mathrm{A}, \mathrm{a}}$ & $18.74^{\mathrm{AB}, \mathrm{a}}$ & $22.00^{\mathrm{A}, \mathrm{a}}$ & 0.112 \\
& $(6.72)$ & $(4.99)$ & $(4.03)$ & \\
Aelite & $19.79^{\mathrm{A}, \mathrm{a}}$ & $19.97^{\mathrm{AB}, \mathrm{a}}$ & $17.60^{\mathrm{A}, \mathrm{a}}$ & 0.492 \\
& $(3.43)$ & $(4.73)$ & $(6.10)$ & \\
Silorane & $23.10^{\mathrm{A}, \mathrm{a}}$ & $24.09^{\mathrm{A}, \mathrm{a}}$ & $8.49^{\mathrm{B}, \mathrm{b}}$ & $<0.001$ \\
& $(5.24)$ & $(4.96)$ & $(7.06)$ & \\
Gradia & $21.72^{\mathrm{A}, \mathrm{a}}$ & $17.10^{\mathrm{B}, \mathrm{a}}$ & $19.85^{\mathrm{A}, \mathrm{a}}$ & 0.098 \\
& $(3.06)$ & $(5.19)$ & $(5.25)$ & \\
p-value & 0.263 & 0.022 & $<0.001$ & \\
\hline
\end{tabular}

Different lowercase letters in rows and uppercase letters in columns indicate statistically significant differences. 
No significant difference was found when comparing the bond strength values of different composite resins polymerized with QTH. The bond strength values of LED-polymerized Filtek Silorane and Gradia Direct Anterior were significantly different from each other $(p=0.022)$. Polymerization with PAC caused the lowest bond strength values for Filtek Silorane among the groups $(p<0.001)$.

Table 4 shows the distribution of failure modes for all groups. For the Aelite group, the QTH and PAC subgroups showed increased numbers of cohesive failures ( $90 \%$ and $70 \%$, respectively), and the LED subgroup showed an increased number of adhesive failures $(70 \%)$. For the Gradia group, polymerization with QTH did not result in a significant difference in the number of adhesive or cohesive failures; however, polymerization with LED or PAC resulted in an increased number of

Table 4. Distribution of Failure Modes

\begin{tabular}{|c|c|c|c|c|c|}
\hline \multirow{2}{*}{ Composite } & \multicolumn{5}{|c|}{ QTH } \\
\hline & Adhesive & Cohesive & Mixed & Total & $p$ \\
\hline Aelite & $0^{\mathrm{B}, \mathrm{b}}(0 \%)$ & $9^{A, a}(90 \%)$ & $1^{A B, b}(10 \%)$ & 10 & $<0.001$ \\
\hline Gradia & $5^{\mathrm{A}, \mathrm{a}}(50 \%)$ & $5^{\mathrm{AB}, \mathrm{a}}(50 \%)$ & $0^{\mathrm{B}, \mathrm{b}}(0 \%)$ & 10 & 0.002 \\
\hline Silorane & $6^{A, a}(60 \%)$ & $3^{\mathrm{B}, \mathrm{ab}}(30 \%)$ & $1^{\mathrm{AB}, \mathrm{b}}(10 \%)$ & 10 & $0.150^{\circ}$ \\
\hline Z550 & $7^{A, a}(70 \%)$ & $1^{B, b}(10 \%)$ & $2^{A, b}(20 \%)$ & 10 & 0.045 \\
\hline Total & 18 (45\%) & 18 (45\%) & $4(10 \%)$ & 40 & \\
\hline$p$-value & 0.009 & 0.009 & 0.046 & & \\
\hline \multirow{2}{*}{ Composite } & \multicolumn{5}{|c|}{ LED } \\
\hline & Adhesive & Cohesive & Mixed & Total & $p$ \\
\hline Aelite & $7^{A, a}(70 \%)$ & $2^{\mathrm{B}, \mathrm{b}}(20 \%)$ & $1^{A, b}(10 \%)$ & 10 & 0.045 \\
\hline Gradia & $6^{A, a}(60 \%)$ & $\mathrm{O}^{\mathrm{B}, \mathrm{b}}(0 \%)$ & $4^{A, a}(40 \%)$ & 10 & 0.010 \\
\hline Silorane & $3^{A, a}(30 \%)$ & $6^{A, a}(60 \%)$ & $1^{A, b}(10 \%)$ & 10 & $0.150^{*}$ \\
\hline Z550 & $8^{A, a}(80 \%)$ & $\mathrm{O}^{\mathrm{B}, \mathrm{b}}(0 \%)$ & $2^{A, b}(20 \%)$ & 10 & 0.001 \\
\hline Total & $24(60 \%)$ & 8 (20\%) & 8 (20\%) & 40 & \\
\hline$p$-value & 0.076 & 0.021 & 0.710 & & \\
\hline \multirow{2}{*}{ Composite } & \multicolumn{5}{|c|}{ PAC } \\
\hline & Adhesive & Cohesive & Mixed & Total & $p$ \\
\hline Aelite & $2^{\mathrm{B}, \mathrm{b}}(20 \%)$ & $7^{A, a}(70 \%)$ & $1^{A, b}(10 \%)$ & 10 & 0.045 \\
\hline Gradia & $1^{\mathrm{B}, \mathrm{b}}(10 \%)$ & $6^{A, a}(60 \%)$ & $3^{A B, a b}(30 \%)$ & 10 & $0.150^{*}$ \\
\hline Silorane & $0^{\mathrm{B}, \mathrm{b}}(0 \%)$ & $7^{A, a}(70 \%)$ & $3^{A, a}(30 \%)$ & 10 & 0.038 \\
\hline Z550 & $6^{A, a}(60 \%)$ & $\left.1^{\mathrm{B}, \mathrm{b}} 10 \%\right)$ & $3^{\mathrm{A}, \mathrm{ab}}(30 \%)$ & 10 & $0.150^{\circ}$ \\
\hline Total & $9(22.5 \%)$ & 21 (52.5\%) & 10 (25\%) & 40 & \\
\hline$p$-value & 0.034 & 0.028 & 0.248 & & \\
\hline
\end{tabular}

Different uppercase letters within columns and lowercase letters within rows show statistically significant differences $(p<0.05)$.

* Statistically significant difference within rows according to the Z-test $(p=0.006)$ adhesive or cohesive failures, respectively (both 60\%). For the Filtek Silorane group, polymerization with QTH resulted in an increased number of adhesive failures $(60 \%)$, whereas polymerization with LED or PAC resulted in an increased number of cohesive failures (60\% or $70 \%$, respectively). For Filtek Z550, the number of adhesive failures was greater than the number of cohesive or mixed failures in all subgroups.

When the failure modes of all specimens were evaluated, the QTH source exhibited the same numbers of adhesive and cohesive failures (45\%). Adhesive failures were more frequent when the LED source was used (60\%), and cohesive failures were more frequent when the PAC source was used (52.5\%).

\section{Discussion}

As an alternative to total replacement, the repair of existing restorations can enhance the longevity of dental restorations. ${ }^{18}$ However, many factors affect the durability of composite-to-composite bond repair. ${ }^{13,14,15}$ This study aimed to evaluate the effect of different light sources on the reparability of one silorane-based and three dimethacrylate-based composite resins. Polymerization with different LCUs resulted in similar bond strength values for methacrylate-based composite resins, but differing values for the silorane-based composite resin. Thus, the null hypothesis was rejected. These results may be helpful for choosing an LCU for repairing composite restorations in everyday situations, wherein it is extremely difficult for the dentist to know whether the restoration to be repaired is methacrylate- or silorane-based.

Specimens in this study were aged with thermal cycling. Aging is common for composite repair tests ${ }^{17,19}$ because repairs usually become necessary months or years after a restoration is placed. The thermal cyclinginduced temperature alterations may affect the composite-to-composite repair strength by decreasing the number of unreacted double bonds on the surface or within the composite. ${ }^{16}$ The success of the repair process is affected by various factors, such as the intermediary or repair material used, and the time after repair. ${ }^{20}$ To focus on the effect of the light source, a uniform repair process was chosen. The Clearfil Repair Kit was used for repair, and the aged composite samples were repaired with the same substrate. 
Using different LCUs, resin composite thicknesses, and light exposure distances may change the physical properties and mechanical behavior of restorative materials. ${ }^{21}$ Depth of cure and microhardness tests have been widely used to assess the relative degree of cure of resins and, thus, the efficiency of light sources. Rode et al..$^{21}$ reported no difference in microhardness up to $2 \mathrm{~mm}$ thickness when LED exposure distances of 0 and $3 \mathrm{~mm}$ were used. In Abate et al..$^{22}$ the distance between the light source and the composite surface did not affect the hardness results when a QTH LCU was used. A common clinical recommendation for the position of the LCU tip is $1 \mathrm{~mm}$ from the resin. ${ }^{23}$ Thus, this guideline was applied in the current study.

The microshear bond strength test was accompanied by an analysis of failure modes. Similar bond strength values for repair were observed for the composite resins when the QTH was used, although their failure modes were significantly different. Using the LED resulted in significantly different bond strength values, but the numbers of adhesive and mixed failures of the groups were similar. It can be concluded that groups with similar bond strength values do not necessarily fail in the same way. Observed differences in the failure mode among the composite resins might be explained by their differences in flexural strength and elastic modulus, which have been suggested to affect the bond strength and failure modes of repaired restorations. ${ }^{24}$

The PAC LCU saved time, while still achieving sufficient bond strength for methacrylate-based composite resins. The observed lower bond strength of PAC-polymerized Filtek Silorane may be attributed to the chemistry of this composite. Curing with PAC may not be adequate for all restorations because rapid polymerization may hinder the development of optimal properties in some materials. ${ }^{25} \mathrm{Kim}$ et al. ${ }^{26}$ suggested a relationship between bond strength and subsurface polymerization. Guiraldo et al. ${ }^{27}$ found that Filtek P90 did not present efficient polymerization in its deepest layers when polymerized with a QTH LCU $\left(900 \mathrm{~mW} / \mathrm{cm}^{2}\right)$. They reported that the degree of subsurface polymerization is greater for methacrylate- than for silorane-based composites, and they recommended increasing the exposure time or using LCUs with greater irradiance to obtain better results for silorane-based composites. Accordingly, the lower bond strength values and greater number of cohesive failures observed in the Filtek Silorane group may be attributed to the rapid polymerization method of PAC, despite its high irradiance.

No previous study has compared the repair bond strength values among different composite resins polymerized with different LCUs. However, the effect of LCUs on dentin bond strength was investigated in several studies, with conflicting results. ${ }^{28,29,30}$ For instance, D'Alpino et al. ${ }^{28}$ concluded that different LCUs influence the restoration bond strength, whereas Amaral et al. ${ }^{29}$ reported that the LCU and method do not significantly affect bond strength. Khosla et al. ${ }^{30}$ evaluated the effects of QTH and LED on the shear bond strengths of silorane- and bis-GMA-based composite resins. The type of LCU did not significantly affect the shear bond strength for bis-GMA-based composite resins when the total-etch technique was used, but the QTH showed the best results for curing silorane-based composites. Nevertheless, the results of these previous studies cannot be compared directly with the data obtained in the present study because those studies evaluated the bond strength to dentine.

In the current study, only one intermediate agent and one polymerization mode were tested. Further research involving the use of different intermediate agents and multiple combinations of polymerization modes is warranted.

\section{Conclusions}

In view of the methodology used and the results obtained, it can be concluded that:

1. Currently available LCUs (QTH, LED, and PAC) promote similar bond strength values in the repair of dimethacrylate-based composites.

2. In the repair of the silorane-based composite, PAC gave the lowest bond strength values; thus, using a QTH or LED device may be the best option for this type of composite.

3. In many cases, dentists do not know the chemical formulation (methacrylate- or siloranebased) of the existing composite resin. For clinical practice, using a QTH or LED device for repairing composite resin restorations would be a good recommendation for all situations. 


\section{References}

1. Manhart J, Chen H, Hamm G, Hickel R. Buonocore Memorial Lecture. Review of the clinical survival of direct and indirect restorations in posterior teeth of the permanent dentition. Oper Dent. 2004 Sep-Oct;29(5):481-508.

2. Hickel R, Manhart J. Longevity of restorations in posterior teeth and reasons for failure. J Adhes Dent. 2001 Spring;3(1):45-64.

3. Gordan VV, Garvan CW, Blaser PK, Mondragon E, Mjor IA. A long-term evaluation of alternative treatments to replacement of resin-based composite restorations: results of a seven-year study. J Am Dent Assoc. 2009 Dec;140(12):1476-84.

4. Foitzik M, Attin T. Filling revision--possibilities and execution. Schweiz Monatsschr Zahnmed. 2004;114(10):1003-11.

5. Peris AR, Mitsui FH, Amaral CM, Ambrosano GM, Pimenta LA. The effect of composite type on microhardness when using quartz-tungsten-halogen (QTH) or LED lights. Oper Dent. 2005 Sep-Oct;30(5):649-54.

6. Caldas DB, Almeida JB, Correr-Sobrinho L, Sinhoreti MA, Consani S. Influence of curing tip distance on resin composite Knoop hardness number, using three different light curing units. Oper Dent. 2003 May-Jun;28(3):315-20.

7. Barghi N, Berry T, Hatton C. Evaluating intensity output of curing lights in private dental offices. J Am Dent Assoc. 1994 Jul;125(7):992-6.

8. Franco EB, Santos PA, Mondelli RF. The effect of different light-curing units on tensile strength and microhardness of a composite resin. J Appl Oral Sci. 2007 Dec;15(6):470-4.

9. Oesterle LJ, Newman SM, Shellhart WC. Rapid curing of bonding composite with a xenon plasma arc light. Am J Orthod Dentofacial Orthop. 2001 Jun;119(6):610-6.

10. Jandt KD, Mills RW, Blackwell GB, Ashworth SH. Depth of cure and compressive strength of dental composites cured with blue light emitting diodes (LEDs). Dent Mater. 2000 Jan;16(1):41-7.

11. Peutzfeldt A, Sahafi A, Asmussen E. Characterization of resin composites polymerized with plasma arc curing units. Dent Mater. 2000 Nov;16(5):330-6.

12. Campbell IM. Introduction to synthetic polymers. Oxford: Science Publications; 1994. 213 p.

13. Tezvergil A, Lassila LV, Vallittu PK. Composite-composite repair bond strength: effect of different adhesion primers. J Dent. 2003 Nov;31(8):521-5.

14. Rathke A, Tymina Y, Haller B. Effect of different surface treatments on the composite-composite repair bond strength. Clin Oral Investig. 2009 Set;13(3):317-23.

15. Bonstein T, Garlapo D, Donarummo J Jr, Bush PJ. Evaluation of varied repair protocols applied to aged composite resin. J Adhes Dent. 2005 Spring;7(1):41-9.

16. Ozcan M, Barbosa SH, Melo RM, Galhano GA, Bottino MA. Effect of surface conditioning methods on the microtensile bond strength of resin composite to composite after aging conditions. Dent Mater. 2007 Oct;23(10):1276-82.
17. Wiegand A, Stawarczyk B, Buchalla W, Tauböck TT, Özcan M, Attin T. Repair of silorane composite--using the same substrate or a methacrylate-based composite? Dent Mater. 2012 Mar;28(3):e19-25.

18. Opdam NJ, Bronkhorst EM, Loomans BA, Huysmans MC. Longevity of repaired restorations: a practice based study. J Dent. 2012 Oct;40(10):829-35.

19. Rinastiti M, Ozcan M, Siswomihardjo W, Busscher HJ. Effects of surface conditioning on repair bond strengths of non-aged and aged microhybrid, nanohybrid, and nanofilled composite resins. Clin Oral Investig. 2011 Oct;15(5):625-33.

20. Shahdad SA, Kennedy JG. Bond strength of repaired anterior composite resins: an in vitro study. J Dent. 1998 Nov;26(8):685-94.

21. Rode KM, Kawano Y, Turbino ML. Evaluation of curing light distance on resin composite microhardness and polymerization. Oper Dent. 2007 Nov-Dec;32(6):571-8.

22. Abate PF, Zahra VN, Macchi RL. Effect of photopolymerization variables on composite hardness. J Prosthet Dent. 2001 Dec;86(6):632-5.

23. Sobrinho LC, Lima AA, Consani S, Sinhoreti MA, Knowles JC. Influence of curing tip distance on composite Knoop hardness values. Braz Dent J. 2000;11(1):11-7.

24. Boaro LC, Goncalves F, Guimaraes TC, Ferracane JL, Versluis A, Braga RR. Polymerization stress, shrinkage and elastic modulus of current low-shrinkage restorative composites. Dental Mater. 2010 Dec;26(12):1144-50.

25. Deb S, Sehmi H. A comparative study of the properties of dental resin composites polymerized with plasma and halogen light. Dental Mater. 2003 Sep;19(6):517-22.

26. Kim JS, Choi YH, Cho BH, Son HH, Lee IB, Um CM, et al. Effect of light-cure time of adhesive resin on the thickness of the oxygen-inhibited layer and the microtensile bond strength to dentin. J Biomed Mater Res B Appl Biomater. 2006 Jul;78(1):115-23.

27. Guiraldo RD, Consani S, Consani RL, Berger SB, Mendes WB, Sinhoreti MA, et al. Comparison of silorane and methacrylate-based composite resins on the curing light transmission. Braz Dent J. 2010;21(6):538-42.

28. D’Alpino PH, Wang L, Rueggeberg FA, Svizero NR, Pereira JC, Pashley DH, et al. Bond strength of resin-based restorations polymerized with different light-curing sources. J Adhes Dent. 2006 Oct;8(5):293-8.

29. Amaral CM, Peris AR, Ambrosano GM, Swift EJ Jr, Pimenta LA. The effect of light-curing source and mode on microtensile bond strength to bovine dentin. J Adhes Dent. 2006 Feb;8(1):41-5.

30. Khosla M, Malhotra N, Mala K. An in vitro evaluation of shear bond strength of silorane and bis-GMA resin-based composite using different curing units. J Conserv Dent. 2012;15(3):278-82. 